\title{
Understanding why the volume of suboxic waters does not increase over centuries of global warming in an Earth System Model
}

\author{
A. Gnanadesikan ${ }^{1,2}$, J. P. Dunne ${ }^{2}$, and J. John ${ }^{2}$ \\ ${ }^{1}$ Department of Earth and Planetary Sciences, Johns Hopkins University, 3400 N. Charles St., Baltimore, MD, USA \\ ${ }^{2}$ NOAA Geophysical Fluid Dynamics Laboratory, Forrestal Campus, Princeton, NJ, USA
}

Correspondence to: A. Gnanadesikan (gnanades@jhu.edu)

Received: 1 July 2011 - Published in Biogeosciences Discuss.: 15 July 2011

Revised: 15 March 2012 - Accepted: 16 March 2012 - Published: 28 March 2012

\begin{abstract}
Global warming is expected to reduce oxygen solubility and vertical exchange in the ocean, changes which would be expected to result in an increase in the volume of hypoxic waters. A simulation made with a full Earth System model with dynamical atmosphere, ocean, sea ice and biogeochemical cycling (the Geophysical Fluid Dynamics Laboratory's Earth System Model 2.1) shows that this holds true if the condition for hypoxia is set relatively high. However, the volume of the most hypoxic (i.e., suboxic) waters does not increase under global warming, as these waters actually become more oxygenated. We show that the rise in dissolved oxygen in the tropical Pacific is associated with a drop in ventilation time. A term-by-term analysis within the least oxygenated waters shows an increased supply of dissolved oxygen due to lateral diffusion compensating an increase in remineralization within these highly hypoxic waters. This lateral diffusive flux is the result of an increase of ventilation along the Chilean coast, as a drying of the region under global warming opens up a region of wintertime convection in our model. The results highlight the potential sensitivity of suboxic waters to changes in subtropical ventilation as well as the importance of constraining lateral eddy transport of dissolved oxygen in such waters.
\end{abstract}

\section{Introduction}

Ten percent of present day ocean volume is characterized by low level of dissolved oxygen (henceforth $\mathrm{O}_{2}$ ) similar to those found in the well-known "dead zones" in the Gulf of Mexico with $35 \%$ of global surface waters overlying "hypoxia" $\left(\mathrm{O}_{2}<88 \mu \mathrm{M} \sim 2 \mathrm{ml}^{-1}\right)$ (Garcia et al., 2010). Under global warming, higher temperatures would be expected to directly lower $\mathrm{O}_{2}$ concentration and enhanced stratification (particularly as a result of high-latitude freshening) would be expected to reduce the flow of well-ventilated surface waters to the interior (Matear et al., 2000; Bopp et al., 2002; Le Quere et al., 2002). Under such circumstances previous modeling studies have suggested that openocean dead zones could greatly expand (Shaffer et al., 2009; Fröhlicher et al., 2009) and indeed observed decreases in $\mathrm{O}_{2}$ have been invoked as evidence of climate change (Stramma et al., 2010).

The complexity of the Earth System's response to climate change, however, suggests that deoxygenation of the ocean is unlikely to be uniform. Matear and Hirst (2003), for example, found that $\mathrm{O}_{2}$ increased at depths associated with tropical hypoxic waters in a long-term simulation of global warming. More recently, Duteil and Oschlies (2011) found that suboxia $\left(\mathrm{O}_{2}\right.$ less then $\left.0.2 \mathrm{ml}^{-1} \sim 8.8 \mu \mathrm{M}\right)$ did not necessarily increase in their global warming simulations. In this paper we examine the physics behind a similar increase in volume and decrease in the intensity of hypoxia in a global warming simulation with an Earth System Model. We demonstrate that the decline in intensity can be explained by changes in the balance between pathways that connect interior waters to the surface. Such changes have previously been shown to explain why tropical waters between 300 and $1500 \mathrm{~m}$ become younger with respect to exchange with the surface under global warming in coupled models (Gnanadesikan et al., 2007). While the application of this method to oxygen cycling is more complex, the conclusion is similar for the bulk of hypoxic waters. In addition, we show that changes in ventilation for Southeast Pacific suboxic waters in this model also involve a change in convection off the Chilean coast spurred by changes in the local heat and freshwater balance. 


\section{Methods}

The model used in this paper is the Geophysical Fluid Dynamics Laboratory (GFDL) Earth System Model 2.1 (ESM2.1). The underlying physical model is an implementation of the GFDL physical climate model CM2.1 (Delworth et al., 2006; Gnanadesikan et al., 2006) which was used for the Intergovernmental Panel on Climate Change's Fourth Assessment report (IPCC AR4). This model consists of an approximately 2 -degree resolution atmosphere with 24 vertical levels atop an approximately 1-degree resolution ocean with 50 vertical levels and a sea ice model with five thickness classes. Considering metrics of relevance to this paper, CM2.1 generally ranks as one of the most skilful IPCC AR4 models in simulating atmospheric climate (Reichler and Kim, 2008), the El Niño Southern Oscillation cycle (van Oldenborgh et al., 2005) and the hydrography of the Southern Ocean (Russell et al., 2006). It does share with many other climate models a bias towards overly thin stratus decks above upwelling zones, resulting in significant warm biases in sea surface temperatures in these regions.

ESM2.1 adopts the parameterizations and settings of CM2.1 for the atmosphere, ocean physics, and sea ice. On the land, the fixed stomatal resistance and albedo used by CM2.1 based on observed land properties is replaced by properties predicted by the LM3v dynamic vegetation model of Shevliakova et al. (2009). Additionally, the absorption of shortwave radiation in ESM2.1 uses the chlorophylldependent absorption scheme of Morel and Antoine (1994) with chlorophyll predicted by the Tracers of Ocean Productivity with Allometric Zooplankton (TOPAZ) code (Dunne et al., 2010; Gnanadesikan et al., 2011). The CM2.1 code uses the same scheme with a climatological chlorophyll taken from the SeaWiFS satellite. The net effects of including prognostic ecosystems on ocean circulation are quite minor.

The ocean model resolution being nominally 1 degree, the lateral transport of passive tracers associated with eddies must be parameterized. This is done using an isoneutral diffusion parameterization (Griffies et al., 1998) with a diffusion coefficient $A_{\text {redi }}=600 \mathrm{~m}^{2} \mathrm{~s}^{-1}$ chosen to limit biases in sea surface temperature. The impacts of the choice of $A_{\text {redi }}$ on circulation are discussed in Gnanadesikan et al. (2006). The realism of this choice of an isotropic, spatiotemporally constant coefficient is considered in more detail in the Conclusions section of this paper.

The version of the ocean biogeochemical model TOPAZ used in ESM2.1 resolves three phytoplankton classes: small/prokaryotic, large/eukaryotic, and diazotrophs. Upon grazing, large phytoplankton are assumed to be packaged into more efficiently exported material than small phytoplankton (Dunne et al., 2005). A fraction of the sinking organic material is associated with denser ballast materials (opal, calcium carbonate, and lithogenic material) and remineralizes only when these materials dissolve. At high $\mathrm{O}_{2}$, the unprotected fraction is remineralized with a constant depth scale of $w_{\text {sink }} / R=180 \mathrm{~m}$ where $w_{\text {sink }}$ is the sinking velocity and $R$ is a remineralization rate. The remineralization rate $R$ is suppressed in the absence of $\mathrm{O}_{2}$ :

$R=\frac{r_{\text {oxic }} \cdot \max \left(\mathrm{O}_{2}, \mathrm{O}_{2 \min }\right)}{K_{\mathrm{O}_{2}}+\mathrm{O}_{2}}$

where $K_{\mathrm{O}_{2}}=20 \mu \mathrm{M}$. This provides for oxygen limitation of oxic respiration down to a minimum value of oxygen $\left(\mathrm{O}_{2 \min }=1 \mu \mathrm{M}\right)$ at which point the decay of organic matter switches over to denitrification at that same rate. Equation (1) represents the contrast in oxic- and denitrification-modulated depth scales between the Mexican and Washington Margins as seen by Devol and Hartnett (2001).

Ocean temperature and salinity in ESM2.1 are initialized from the CM2.1 1860 control run after $2000 \mathrm{yr}$ of run. Ocean nutrients and $\mathrm{O}_{2}$ in ESM2.1 are initialized from World Ocean Atlas 2001 observations (http://www.nodc.noaa.gov/ OC5/WOA01/pr_woa01.html). ESM2.1 is then then run with interactive chlorophyll and an interactive land biosphere but with radiatively active gasses fixed at 1860 levels for another $1600 \mathrm{yr}$. The resulting climate and biospheric state is used as the basis for several runs, summarized in Table 1. The first of these runs is what we will refer to as the 1860 Control run. In this run all radiative active gasses are held fixed and the model is run for $540 \mathrm{yr}$. A second "historical" run is initialized in Year 101 of the 1860 Control after which historic volcanic, aerosol and well-mixed greenhouse gas forcings are applied from years 1861-2000. Finally a number of "scenario" runs are made in which the impacts of future changes in greenhouse gasses can be studied.

The main focus in this paper will be on the relatively aggressive A2 scenario (Nakicenovic et al., 2000) in which greenhouse gas levels rise sharply until 2100. After this point we assume stabilization of greenhouse gas levels, so that our simulation exhibits a maximum radiative imbalance at the top of the atmosphere of about $2.15 \mathrm{~W} \mathrm{~m}^{-2}$ into the Earth relative to the 1860 Control from years 2081-2100. This is in contrast to Schmittner et al. (2008) who instead prescribe a linear decrease in emissions from 2100 to 2300 leading to a more than doubling of $\mathrm{CO}_{2}$ concentrations. As a result, the ESM2.1 runs experience much less greenhouse forcing and heat uptake into their third century relative to the Schmittner et al. (2008) simulations. We examine both the evolution of the $\mathrm{A} 2$ run over $300 \mathrm{yr}$ as well as its averaged behavior over years 2281-2300. Full term balances of were run for the 1860 Control, Historical and A2 runs.

In order to evaluate the robustness of changes seen in the A2 run, we also consider a suite of runs made using the A1B scenario. The greenhouse gas forcing in these runs is essentially identical to the A2 runs until the year 2050. From 2050 to 2100 carbon dioxide in the A1B scenario increases from 532 to $717 \mathrm{ppmv}$ while in the A2 scenario it increases from 532 to 856 ppmv. The full A1B scenario (fourth line, Table 1) is initialized identically to the A2 run, and thus represents 
Table 1. Summary of the nine ESM2.1 runs used in this paper.

\begin{tabular}{lllll}
\hline Scenario & Initialized from & $\begin{array}{l}\text { Radiative forcing } \\
\mathrm{CO}_{2} / \text { Aerosols }\end{array}$ & $\begin{array}{l}\Delta \text { Net TOA radiation } \\
\text { 2080-2100/2280-2300 }\end{array}$ & $\begin{array}{l}\Delta \mathrm{CO}_{2} \text { affects } \\
\text { Land plants/pH }\end{array}$ \\
\hline 1860 Control & 1600 Year Spinup & 286 ppmv/Control & $0.0 / 0.0$ & $\mathrm{~N} / \mathrm{N}$ \\
Historical & 1860 Yr 101 & Historical & N/A & Y/Y \\
A2 & Historical, 2001 & A2 & $2.15 / 1.15$ & Y/Y \\
A1B Full & Historical,2001 & A1B & $1.73 / 0.93$ & Y/Y \\
A1B Rad Only & 1860 Yr 101 & Historical, A1B & $1.62 / 0.97$ & $\mathrm{~N} / \mathrm{N}$ \\
A1B Rad + Land & 1860 Yr 101 & Historical, A1B & $1.59 / 0.92$ & $\mathrm{Y} / \mathrm{N}$ \\
A1B Rad + Ocean & 1860 Yr 101 & Historical, A1B & $1.61 / 0.91$ & $\mathrm{~N} / \mathrm{Y}$ \\
A1B Land + Ocean & 1860 Yr 101 & 286/Control & $0.09 / 0.00$ & $\mathrm{~N} / \mathrm{N}$ \\
A1B Ocean & 1860 Yr 101 & 286/Control & $-0.08 / 0.06$ & $\mathrm{~N} / \mathrm{Y}$ \\
\hline
\end{tabular}

a measure of how robust the initial response of oxygen to warming is in the A2 run. An additional set of runs were made in which the rise of carbon dioxide since 1860 was allowed to affect some subset of the radiative balance, land biosphere, and ocean biosphere (via changing ocean $\mathrm{pH}$ ). These runs (lines 5-9 in Table 1) were initialized from year 101 of the 1860 Control and were run through consistent historical and A1B emissions scenarios out to year 2300. As term balances were not saved for these runs, we will concentrate on their evolution during years 2001-2100.

\section{Results}

\subsection{Control $\mathrm{O}_{2}$ simulation}

We begin by considering the output of the 1860 control of ESM2.1 averaged over years 221-240, corresponding to years 1981-2000 of the historical run. At $300 \mathrm{~m}$ depth hypoxic waters $\left(\mathrm{O}_{2}<2 \mathrm{ml} \mathrm{l}^{-1} \sim 88 \mu \mathrm{M}\right.$; a commonly used definition of where low $\mathrm{O}_{2}$ starts to affect fish) are found along the eastern edges of the tropical ocean basins, as well as in the North Pacific and Northern Indian Ocean (Fig. 1a). These regions are unique in being advectively disconnected from regions of deep wintertime convection where oxygenated surface waters are injected into the ocean interior (Luyten et al., 1983; Gnanadesikan et al., 2007). The model is largely able to simulate the pattern of high and low $\mathrm{O}_{2}$ (Fig. 1b), with a spatial correlation (computed by interpolating the $\mathrm{O}_{2}$ data to the model grid and using volume-weighted averaging) of 0.88 at $300 \mathrm{~m}$ and 0.83 globally. The model captures the location of the tropical oxygen minimum zones in the eastern basins relatively well. Globally, the modeled hypoxic volume is $157 \mathrm{M} \mathrm{km}^{3}$, comparable to the observed $148 \mathrm{M} \mathrm{km}^{3}$.

However, when suboxia $\left(\mathrm{O}_{2}<0.2 \mathrm{ml}^{-1} \sim 8.8 \mu \mathrm{M}\right.$; the realm where bacterial cycling moves to alternative electron receptors such as nitrogen) is considered, the model predicts far too large a volume. Recent work (Bianchi, 2011) shows that the volume of waters with $\mathrm{O}_{2}$ less than $20 \mu \mathrm{M}$ is $17 \mathrm{M} \mathrm{km}^{3}$. The volume of waters with concentrations less than $5 \mu \mathrm{M}$ is $4 \mathrm{M} \mathrm{km}^{3}$. Taking the $20 \mu \mathrm{M}$ contour as a boundary, the ESM2.1 1860 Control predicts a volume of $61 \mathrm{M} \mathrm{km}^{3}$, a factor of 3.5 too large. A similar overprediction of suboxia was reported by Matear and Hirst (2003) in their model. In our simulation, the overprediction is largely due to the creation of suboxic waters throughout the water column in the Peru, Panama and Guatemala Basins which appear to be far too isolated in our model. If we focus on depths above $1000 \mathrm{~m}$ (where most suboxic waters in the present-day ocean are found) the volume of suboxic waters within the Pacific is $15.5 \mathrm{M} \mathrm{km}^{3}$, slightly above the range of $13.9-14.5 \mathrm{M} \mathrm{km}^{3}$ found by Bianchi (2011). Waters below $1000 \mathrm{~m}$ in the Pacific contribute $37.4 \mathrm{M} \mathrm{km}^{3}$ to the total and the Atlantic contributes another $5 \mathrm{M} \mathrm{km}^{3}$.

Almost all of the waters that have $\mathrm{O}_{2}$ below $20 \mu \mathrm{M}$ in our simulation proceed to suboxia. This contrasts with the data (Bianchi, 2011) despite the suppression of remineralization in such waters. It is unlikely that this excessive progression to suboxia arises from large-scale primary productivity being biased high. As noted in Gnanadesikan et al. (2011), the model compares well against the zonal integral of primary production estimated from satellite. Additionally, the model matches the observed globally averaged vertical profile of $\mathrm{O}_{2}$, suggesting that it is the regional structure of $\mathrm{O}_{2}$ redistribution at intermediate depths rather than the total amount of consumption at those depths that are in error.

Besides the excessive suboxia/hypoxia in the East Pacific, the main failure of the model comes from its inability to develop very low $\mathrm{O}_{2}$ in the North Pacific. This failure is associated with excessive production of weakly stratified North Pacific Mode Water to the east of Japan. High values of $\mathrm{O}_{2}$ in the regions ventilated by this watermass result in an underestimate of hypoxic volume in this region that largely compensates the overestimate of hypoxic volume in the deep tropical Pacific.

Using a dynamical model allows us to quantify the role of various terms in the model $\mathrm{O}_{2}$ budget. The balance of $\mathrm{O}_{2}$ 


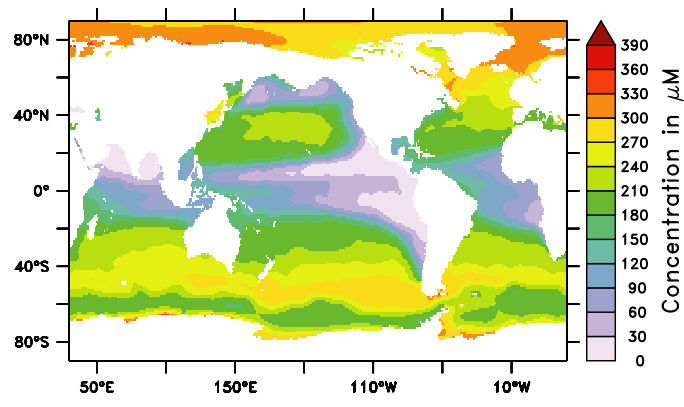

(a) Observed Oxygen

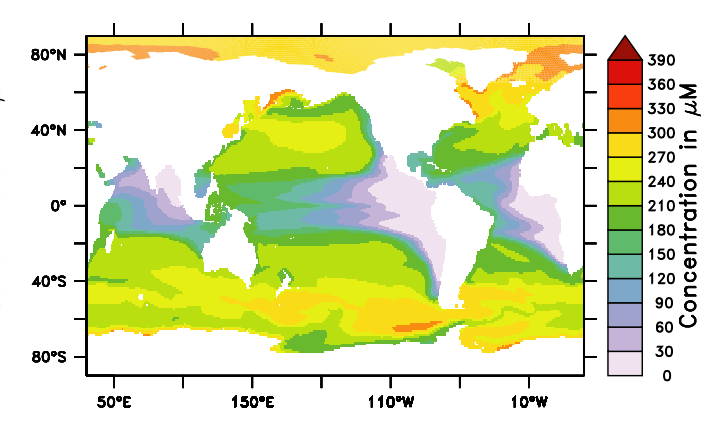

(b) Modeled Oxygen

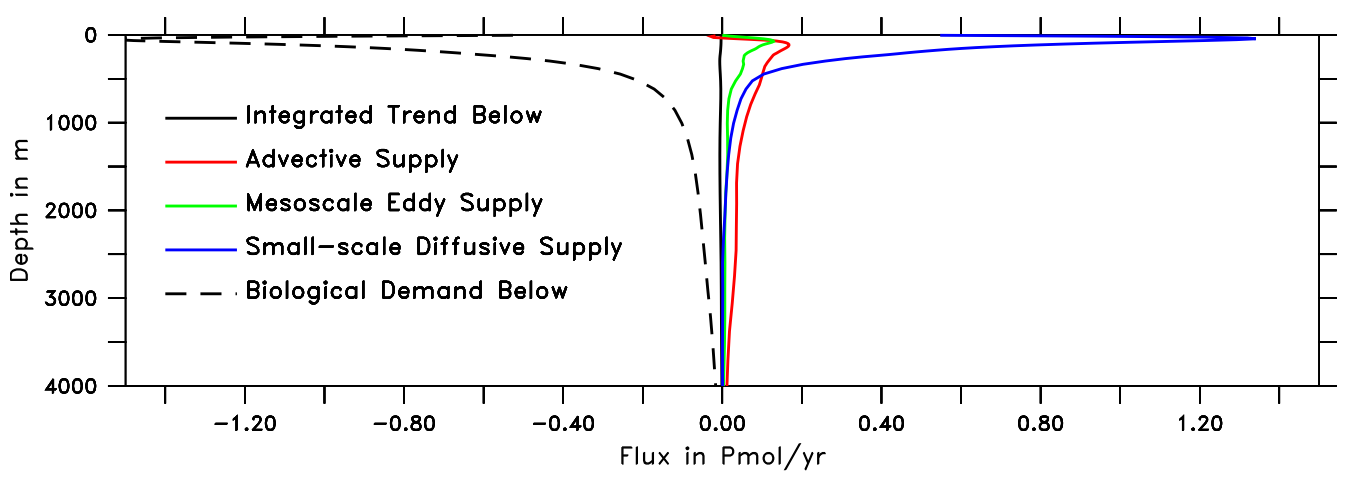

(c) Oxygen Budget, Control

Fig. 1. Current dissolved oxygen distribution and budget. (a) Observed $\mathrm{O}_{2}$ in $\mu \mathrm{M}$ at $300 \mathrm{~m}$. (b) Modeled $\mathrm{O}_{2}$ in $\mu \mathrm{M}$ at $300 \mathrm{~m}$. (c) Vertically resolved budget of $\mathrm{O}_{2}$ in 1860 Control simulation. Time shown is years 221-240, corresponding to years 1981-2000 historical run. Solid black line is the integrated trend of $\mathrm{O}_{2}$ below a given depth-near-zero values show that the model is essentially in steady state. Red, green and blue lines show the supply of $\mathrm{O}_{2}$ to deeper waters (corresponding to the downward flux) associated with advection, mesoscale eddy fluxes, and small-scale diffusion respectively. Dashed black line shows the net biological source/sink of $\mathrm{O}_{2}$ below a given depth. The sum of the supply lines and source equals the trend.

below a given depth can be written as

$\int_{-D}^{z} \frac{\partial \mathrm{O}_{2}}{\partial t} \mathrm{~d} V=\int_{-D}^{z} J_{\mathrm{O}_{2}} \mathrm{~d} V+A(z)+E(z)+D(z)$

where the integrals are taken over the entire ocean below depth $z$. In Eq. (2) the first term on the left hand side represents the integrated trend, $J_{\mathrm{O}_{2}}$ represents the net source/sink of $\mathrm{O}_{2}$ at each point. $A(z)$ represents the downward flux of $\mathrm{O}_{2}$ associated with large-scale flow resolved by the model. $E(z)$ is the downward flux of $\mathrm{O}_{2}$ associated with neutral diffusion, the parameterized mixing associated with mesoscale eddies with length scales of tens of $\mathrm{km} . D(z)$ is the downward flux of $\mathrm{O}_{2}$ due to small-scale diffusive transport processes with length scales comparable to the mixed layer depth. We can then rewrite Eq. (2) as

$T(z)=S(z)+A(z)+E(z)+D(z)$

so that the downward fluxes on the right-hand side of the equation may either balance an implied $\mathrm{O}_{2}$ demand $(S(z))$ or result in an integrated trend $T(z)$. Fig. 1c shows the terms in Eq. (3) averaged over a twenty year period in the control run. $T(z)$ (black line) is negligible throughout the water column, indicating that the model is in steady state. This steady-state balance is achieved by a negative $S(z)$ (dashed black line) being balanced by a different mix of physical fluxes of $\mathrm{O}_{2}$ at different depths. Near the surface, the dominant flux is largely the small-scale diffusive flux $D(z)$ (blue line), whereas below $2000 \mathrm{~m}$ it is largely the advective flux $A(z)$ (red line). Note that the mesoscale eddy flux of $\mathrm{O}_{2}$ $E(z)$ (green line) acts in the same direction as the small-scale diffusive flux, but is much smaller in magnitude.

\subsection{Future changes}

The net historical changes in $\mathrm{O}_{2}$ relative to the 1860 Control run are relatively small, as the warming due to greenhouse gasses is largely counterbalanced by a drift towards lower temperatures associated with the inclusion of volcanic aerosols. However, as greenhouse gasses increase during the 21 st century, $\mathrm{O}_{2}$ drops as well. Time series of the relative change of global $\mathrm{O}_{2}$ concentrations under the $\mathrm{A} 2$ scenario show a basically monotonic decrease of $10 \%$ by year 2300 (Fig. 2a, black line). This decline is not primarily due to warming, as the oxygen saturation (Fig. 2a magenta 


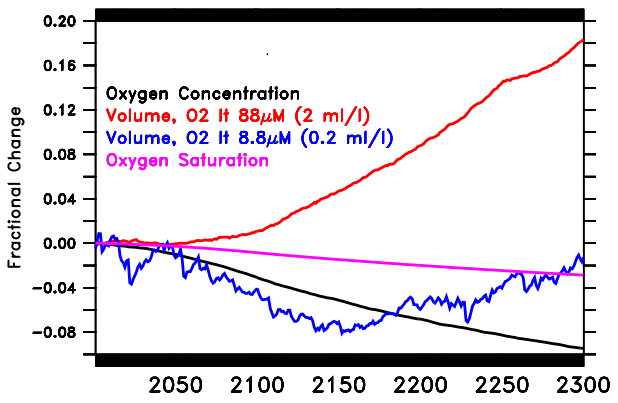

(a) Relative Changes (A2 Scenario)

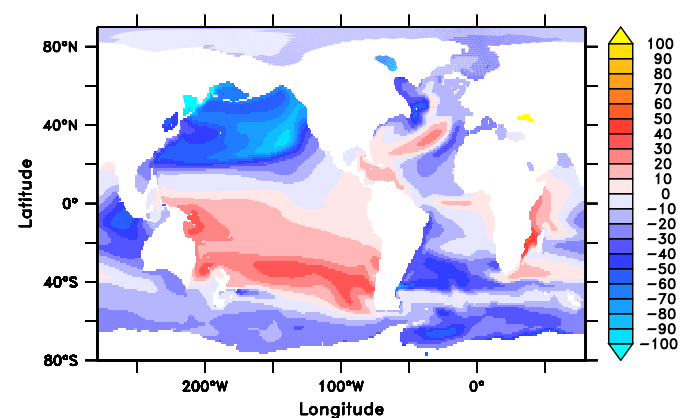

(c) Oxygen Change $\left(\mathrm{mmol} / \mathrm{m}^{3}\right) 2281-2300,800 \mathrm{~m}$

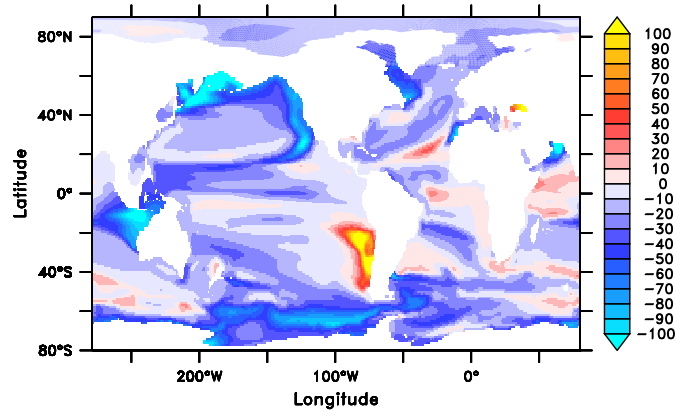

(b) Oxygen Change $\left(\mathrm{mmol} / \mathrm{m}^{3}\right) 2281-2300,300 \mathrm{~m}$

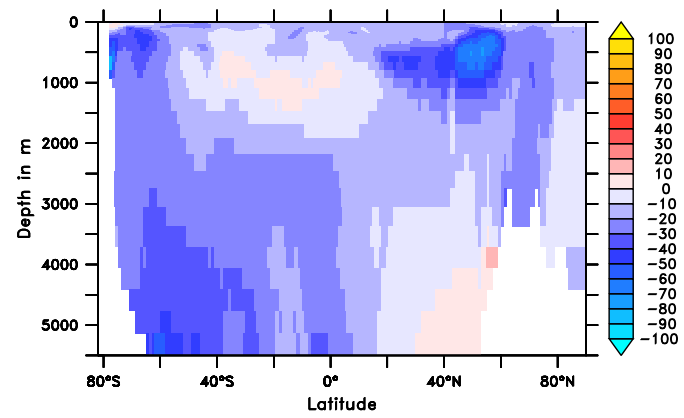

(d) Oxygen Change $\left(\mathrm{mmol} / \mathrm{m}^{3}\right)$ 2281-2300, Zonal Ave.

Fig. 2. Oxygen changes under the $\mathrm{A} 2$ scenario. (a) Relative changes in $\mathrm{O}_{2}$ inventory (black line), $\mathrm{O}_{2}$ inventory in equilibrium with the atmosphere (magenta line), volume of hypoxic water (red line) and volume of suboxic water (blue line) relative to years 1981-2000 of historical run. (b) $\mathrm{O}_{2}$ change ( $\mathrm{mmol} \mathrm{m}^{-3}$ ) at $300 \mathrm{~m}$ depth betwen years 2281-2300 in A2 run and corresponding years from 1860 control. (c) $\mathrm{O}_{2}$ change $\left(\mathrm{mmol} \mathrm{m}^{-3}\right.$ ) at $800 \mathrm{~m}$ depth between years 2281-2300 in A2 run and corresponding years from 1860 control. (d) Zonally averaged $\mathrm{O}_{2}$ change $\left(\mathrm{mmol} \mathrm{m}^{-3}\right)$ between years 2281-2300 in A2 run and corresponding years from 1860 control.

line, corresponding to the $\mathrm{O}_{2}$ content in equilibrium with the atmosphere) drops only by around $2.8 \%$. These results are consistent with those previously reported by Bopp et al. (2002) and Matear and Hirst (2003), who also found that only about $1 / 4$ of the $\mathrm{O}_{2}$ depletion could be directly attributed to warming. The volume of hypoxic water grows monotonically by $18 \%$ over this same time period (Fig. 2a, red line). By contrast, the volume of suboxic water experiences a more subtle response to climate change. Similar to the low-diffusivity subset of the Duteil and Oschlies (2011) simulations, our model decreases the volume of suboxic water under global warming in the 21 st century. The suboxic water volume reaches a minimum in the 22 nd century and starts to rise as $\mathrm{CO}_{2}$ stabilizes after 2100 (blue line, Fig. 2a). Even at year 2300, the volume of suboxic waters is slightly lower in our climate change case than in the 1860 control. In what follows, we will consider changes in concentrations and budgets between the A2 scenario averaged over years 22812300 and the corresponding years from the 1860 Control (521-540).

Examining the changes in oxygen at $300 \mathrm{~m}$ (Fig. 2b) and at $800 \mathrm{~m}$ (Fig. 2c) we see that $\mathrm{O}_{2}$ levels in the heart of a number of oxygen minimum zones (though most strongly in the Southeast Pacific) are higher 2281-2300 than in the control, thus explaining the decline in the suboxic volume. The increase in the Southern Hemisphere also shows up in an eastwest average of the $\mathrm{O}_{2}$ change (Fig. 2d). $\mathrm{O}_{2}$ change can be broken into two components, one due to the change in oxygen solubility (Fig. 3a) and a residual component dominated by changes in biogeochemical cycling (Fig. 3b). In the regions where an increase in $\mathrm{O}_{2}$ is seen in years 2281-2300 of A2 relative the the control the dominant term is this second, primarily biological, component. Below the euphotic zone, an increase in the $\mathrm{O}_{2}$ concentration associated with biogeochemical cycling is likely to be the result of one of two mechanisms, a decrease in the rate at which $\mathrm{O}_{2}$ is consumed by remineralization, or a decrease in the average time required for waters to travel from the surface to the region - the ventilation time. A decrease in the ventilation time would mean that waters would have less time to accumulate an $\mathrm{O}_{2}$ deficit.

The average ventilation time can be estimated using a tracer known as ideal age, which is set to zero in the surface layer and ages at a rate of $1 \mathrm{yr} \mathrm{yr}^{-1}$ below that (resulting in an age with units of years). Contours of the ideal age change under global warming are plotted over the residual $\mathrm{O}_{2}$ change in Fig. 3b, illustrating that zero contours for the two fields largely overlie each other. A scatterplot of the $\mathrm{O}_{2}$ change vs. age change (Fig. 3c) also shows a strong relationship 


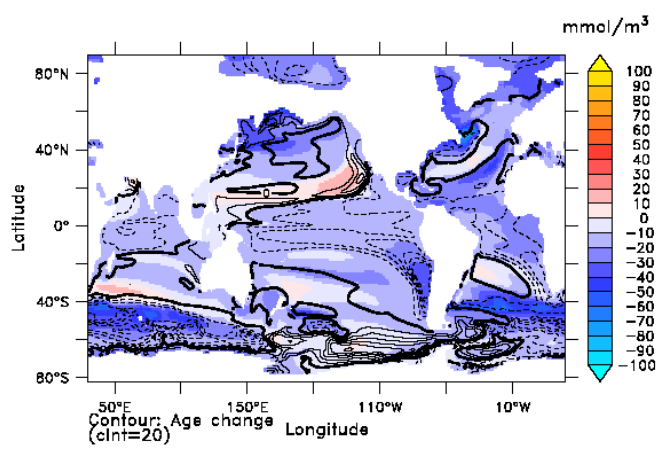

(a) Saturation 02 and Age Change, $300 \mathrm{~m}$

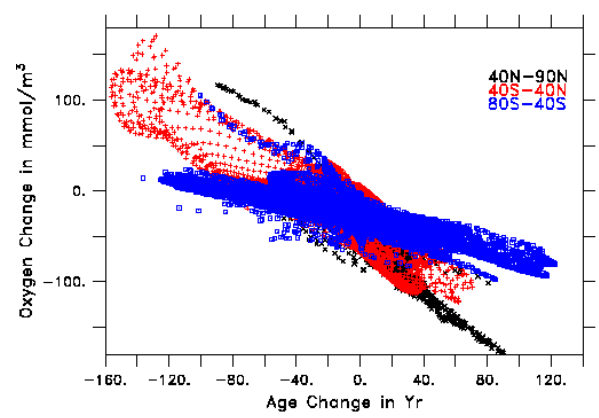

(c) Oxygen change vs. Age Change

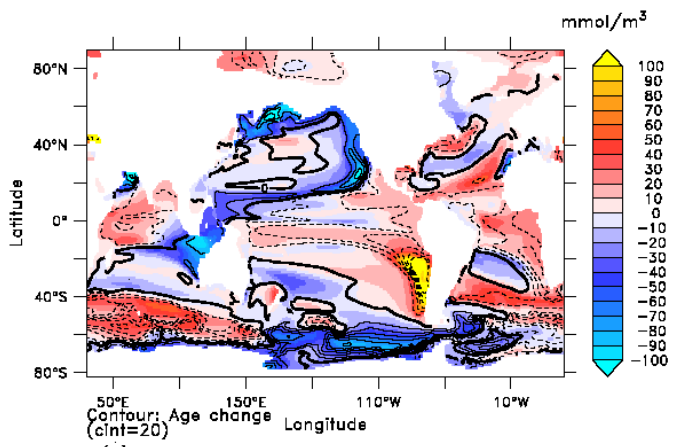

(b) Non-saturation 02 and Age Change, 300m

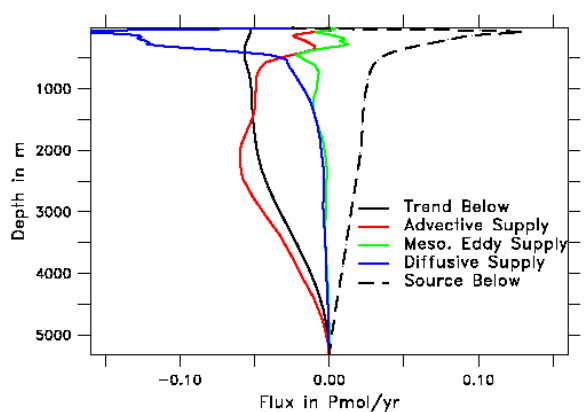

(d) Oxygen Budget Changes (A2-Control)

Fig. 3. (a) Change in the $\mathrm{O}_{2}$ saturation in in $\mu \mathrm{M}$ at $300 \mathrm{~m}$ from years $2281-2300$ under the $\mathrm{A} 2$ scenario relative to corresponding years in the 1860 Control scenario. Primarily due to change in temperature. Contours of the change in ideal age in years are overlaid (dashed contours negative, solid contours positive, bold contour zero line, contour interval $=20 \mathrm{yr}$ ). (b) Change in the $\mathrm{O}_{2}$ concentration at $300 \mathrm{~m}$ in $\mu \mathrm{M}$ at years 2280-2300 with oxygen saturation effects removed and ideal age change overlaid. Note the correspondence between regions that are getting older/younger and less/more oxygenated. (c) Scatterplot of $\mathrm{O}_{2}$ change vs. age change. (d) Change in the $\mathrm{O}_{2}$ budget.

between the two. Regions that are getting older have decreased $\mathrm{O}_{2}$ while regions getting younger have increased $\mathrm{O}_{2}$. The age of water at a given point represents an integral of contributions from a large number of pathways from the surface. Some pathways connect the surface to the interior relatively directly on short time scales while others, generally associated with upwelling of deep water, require hundreds or even thousands of years to travel from the surface to a particular point. Ideal age decreases in the mid-depth tropics have been seen under global warming in a number of climate models (Bryan et al., 2006; Gnanadesikan et al., 2007; Duteil and Oschlies, 2011). These models predict an overall slowdown in the ocean overturning circulation in a warmer world, so that the upwelling arm of the overturning moves a smaller quantity of old water into intermediate depths.

As shown in Fig. $3 c$ the correlation between $\mathrm{O}_{2}$ change and age change is stronger when applied over specific latitude bands. Between $40^{\circ} \mathrm{S}$ and $40^{\circ} \mathrm{N}$ at $300 \mathrm{~m}$ (red points) the slope of the $\mathrm{O}_{2}$-age line is a little more than $1 \mu \mathrm{M} \mathrm{yr}^{-1}$, with increases in $\mathrm{O}_{2}$ concentration of up to $100 \mu \mathrm{M}$ associated with age drops of more than $80 \mathrm{yr}$. In terms of area, regions where the total $\mathrm{O}_{2}$ decreases make up $70 \%$ of the area between $40^{\circ} \mathrm{S}$ and $40^{\circ} \mathrm{N}$ at $300 \mathrm{~m}$ depth. However, if only the non-saturation component is considered, approximately $60 \%$ of the points at $300 \mathrm{~m}$ shift towards higher $\mathrm{O}_{2}$ (com- pared with about $50 \%$ shifting towards lower age). In the low-latitude Pacific and Atlantic, the increase in $\mathrm{O}_{2}$ is largely found in regions where it is already low, while the decreases are largely located along the edge of the gyres were $\mathrm{O}_{2}$ is relatively high.

In the North Pacific there is a large decrease in $\mathrm{O}_{2}$ (Fig. 2b), with most of the black dots in Fig. 3c lying below zero. While some of this decrease is associated with warming (so that points which get younger still lose $\mathrm{O}_{2}$ ) the strong correlation with age suggests that there is an imprint of biological cycling as well. As discussed by Rykaczewski and Dunne (2010) the increase in age is largely the result of a westward shift of the convective area supplying $\mathrm{O}_{2}$ to the thermocline. This shift results in an increase in the transit time of waters from the convective outcrop to the boundary regions, allowing more time for $\mathrm{O}_{2}$ to be drawn down.

Finally, if we look at the Southern Ocean (blue dots, Fig. 3c) we see a much stronger response in age than in $\mathrm{O}_{2}$. Within the Southern Ocean, an age range of around $200 \mathrm{yr}$ (vertical axis) corresponds to an $\mathrm{O}_{2}$ change of around $60 \mu \mathrm{M}$. The disproportionate sensitivity of the deep Southern Ocean overturning to warming and freshening results from the strong dependence of stratification in this region on the hydrological cycle. 
On a global scale, changes in the supply terms show a complicated picture. At depth, the integrated trend in $\mathrm{O}_{2}$ burden $T(z)$ (Fig. 3d, solid black line) becomes more negative as one moves up into the water column from the bottom, corresponding to a lowering of $\mathrm{O}_{2}$. At the base of the thermocline (about $700 \mathrm{~m}$ ), however, this line becomes more or less constant with depth, so that $\mathrm{O}_{2}$ levels are no longer decreasing at these levels. Changes to the advective supply of $\mathrm{O}_{2} A(z)$ match up well with the deep trend in terms of pattern and magnitude below $2000 \mathrm{~m}$, explaining almost all of the change. Between 2000 and $700 \mathrm{~m}$ however, we see that the advective supply curve starts to move to the right. This pattern means that the net advective tendencies at these depths are positive because advection is causing the waters to become more oxygenated. As noted in Gnanadesikan et al. (2007) this is also the pattern of change seen for age. The diffusive supply grows steadily more negative through most of the water column, so that small-scale diffusion is generally causing the waters to become less oxygenated as expected.

By contrast, changes in the biological consumption of $\mathrm{O}_{2}$ $S(z)$ (Fig. 3d, dashed black line) are generally positive, so that the change in biological cycling acts to make the deep ocean more oxygenated. The reduction in deep tropical upwelling and high latitude reduction in small-scale mixing due to stratification combine to reduce the supply of nutrients to the surface ocean and reduce the globally averaged rates of biological productivity (Steinacher et al., 2010). This in turn reduces $\mathrm{O}_{2}$ consumption in the deep ocean. In a global sense then, while advection is most qualitatively consistent with negative changes in $\mathrm{O}_{2}$ at depth and positive changes at mid-depth, diffusion and production also play key roles in the overall balance.

Limiting our analysis to the region from $40^{\circ} \mathrm{S}$ to $5^{\circ} \mathrm{N}$ and 300 to $1500 \mathrm{~m}$, we examine the change in the budget terms for trend, large scale advection, small-scale diffusion, mesoscale eddies and source. In order to make comparisons easier, in Table 2 we normalize all terms by the biological consumption of $\mathrm{O}_{2}$ in the control run. We keep the volume over which we integrate fixed when comparing the control and global warming runs, so that any differences reflect changes in supply rather than changes in the volume of integration.

In the control simulation there is initially a small negative trend in $\mathrm{O}_{2}$ ( $1.3 \%$ of the oxygen consumption). This trend arises because advection, small-scale diffusion and mesoscale eddies together balance only $98.7 \%$ of the source over this volume, with advection accounting for the bulk of the supply. Under global warming, the trend switches sign because there is less oxygen consumption and more advective supply in these waters. In contrast, both the small-scale diffusive supply and mesoscale eddy supply drop sharply. Examination of the pattern of the change in advective supply reveals that it is largely driven by a decline in net upwelling across $1500 \mathrm{~m}$. The fact that advection supplies more $\mathrm{O}_{2}$ but not more nutrients to drive higher consumption is consistent with the picture seen in the global average budget (Fig. 3d). It also matches the previous analysis for ideal age, with more influence from high- $\mathrm{O}_{2}$, low-nutrient, young surface waters and less from the older low- $\mathrm{O}_{2}$, high-nutrient, deep waters.

We now turn to the volume occupied by waters with different $\mathrm{O}_{2}$ concentrations in the control run between between 300 and $1500 \mathrm{~m}$ in the Southern Hemisphere. The 3rd line in Table 2 shows the budget for the hypoxic waters in this region in the control run, and the and 4th line in Table 2 shows how the budget changes for this fixed volume. We note that focussing on hypoxic waters alone gives a different sense of the important balances. This is partly because, in steady state, the mean advective flux of $\mathrm{O}_{2}$ across any fixed surface of $\mathrm{O}_{2}$ must be zero (any advective flux in is balanced by advective flux out somewhere else). However, there can still be time-varying advective fluxes across a mean surface as the oxygen contour is pushed back and forth across the mean position with time.

In contrast to using a fixed depth range, computing the oxygen budget within a volume bounded by a fixed $\mathrm{O}_{2}$ contour shifts the dominant supply of $\mathrm{O}_{2}$ to the parameterized mesoscale eddy term. For hypoxic waters, this term balances $65.7 \%$ of the $\mathrm{O}_{2}$ demand of $50.5 \mathrm{Tmol} \mathrm{yr}^{-1}$ in the control run. The proportion increases as one moves to more and more oxygen-deficient waters so that in the suboxic waters (7th and 8th lines in Table 2) the parameterized mesoscale eddy flux than $80 \%$ of the $\mathrm{O}_{2}$ consumption of $9.7 \mathrm{Tmol} \mathrm{yr}^{-1}$ in the control run. Isopycnal diffusion is much more important in these relatively stagnant "shadow zone" regions that are isolated from surface outcrops (Luyten et al., 1983).

As one moves to waters characterized by lower and lower $\mathrm{O}_{2}$ concentrations in the control run, the sensitivity of remineralization to global warming becomes noticeably different compared with the volume as a whole. In hypoxic waters, oxygen consumption decreases by $2.7 \%$ under global warming. In suboxic waters, by contrast, oxygen consumption actually rises by $28.7 \%$ under global warming, with the relative increase becoming even larger as one moves to lower oxygen concentrations. This rise is a consequence of rising $\mathrm{O}_{2}$ levels. As expected from Eq. (1) higher $\mathrm{O}_{2}$ concentrations allow for higher rates of remineralization in the suboxic zone. Such a rise in remineralization rate may be a model artifact as the suppression of the remineralization rate in the 1860 Control results in excessive spreading of the oxygen minimum zones in the vertical.

The reason that the rise in oxygen consumption does not result in a decrease in $\mathrm{O}_{2}$ concentration is that the diffusive supply of $\mathrm{O}_{2}$ increases. As with the remineralization, this increase becomes more and more extreme for waters which are more depleted in the control. For suboxic waters, the mesoscale eddy supply rises by $2.5 \mathrm{Tmol} \mathrm{yr}^{-1}$ (a change equivalent to about $25 \%$ of the initial consumption). The small-scale diffusive supply almost doubles, increasing by $0.7 \mathrm{Tmol} \mathrm{yr}^{-1}$. These increases compensate both the increase in consumption and a small decrease in advective supply. 
Table 2. $\mathrm{O}_{2}$ budget for the region $40^{\circ} \mathrm{S}-5^{\circ} \mathrm{N}, 300-1500 \mathrm{~m}$ that shows an increase in oxygen concentration in Fig. 2 . A2 run is averaged from years 2281-2300. All terms are given as a percentage of the oxygen consumption over the relevant volume in the control run integrated from years 221-240. The volume used to compute budgets in the A2 run comprises exactly the same points as those used to compute budgets in the control run.

\begin{tabular}{|c|c|c|c|c|c|}
\hline & Source & Trend & Advection & $\begin{array}{r}\text { Small-scale } \\
\text { mixing }\end{array}$ & $\begin{array}{l}\text { Mesoscale eddy } \\
\text { transport }\end{array}$ \\
\hline All waters: Control & 100 & -1.3 & 63.8 & 22.5 & 12.5 \\
\hline All waters: A2 & 91.3 & 0.4 & 77.7 & 10.4 & 3.6 \\
\hline $\mathrm{O}_{2}<88 \mu \mathrm{M}$ in Control & 100 & -2.4 & 19.8 & 12.1 & 65.7 \\
\hline $\mathrm{O}_{2}<88 \mu \mathrm{M}$ in Control: $\mathrm{A} 2$ & 97.3 & -0.2 & 24.6 & 13.5 & 59.0 \\
\hline $\mathrm{O}_{2}<20 \mu \mathrm{M}$ in Control & 100 & -1.1 & 13.7 & 8.5 & 76.7 \\
\hline $\mathrm{O}_{2}<20 \mu \mathrm{M}$ in Control: $\mathrm{A} 2$ & 109.0 & 0.0 & 11.2 & 15.1 & 82.4 \\
\hline Suboxic waters Control & 100 & -0.5 & 10.4 & 8.1 & 81.9 \\
\hline Suboxic waters in Control: A2 & 128.7 & 0.9 & 7.3 & 15.3 & 107.0 \\
\hline $\mathrm{O}_{2}<5 \mu \mathrm{M}$ in Control & 100 & -0.1 & 5.4 & 8.3 & 86.2 \\
\hline $\mathrm{O}_{2}<5 \mu \mathrm{M}$ in Control: $\mathrm{A} 2$ & 152.1 & 1.8 & 6.9 & 10.8 & 136.2 \\
\hline
\end{tabular}
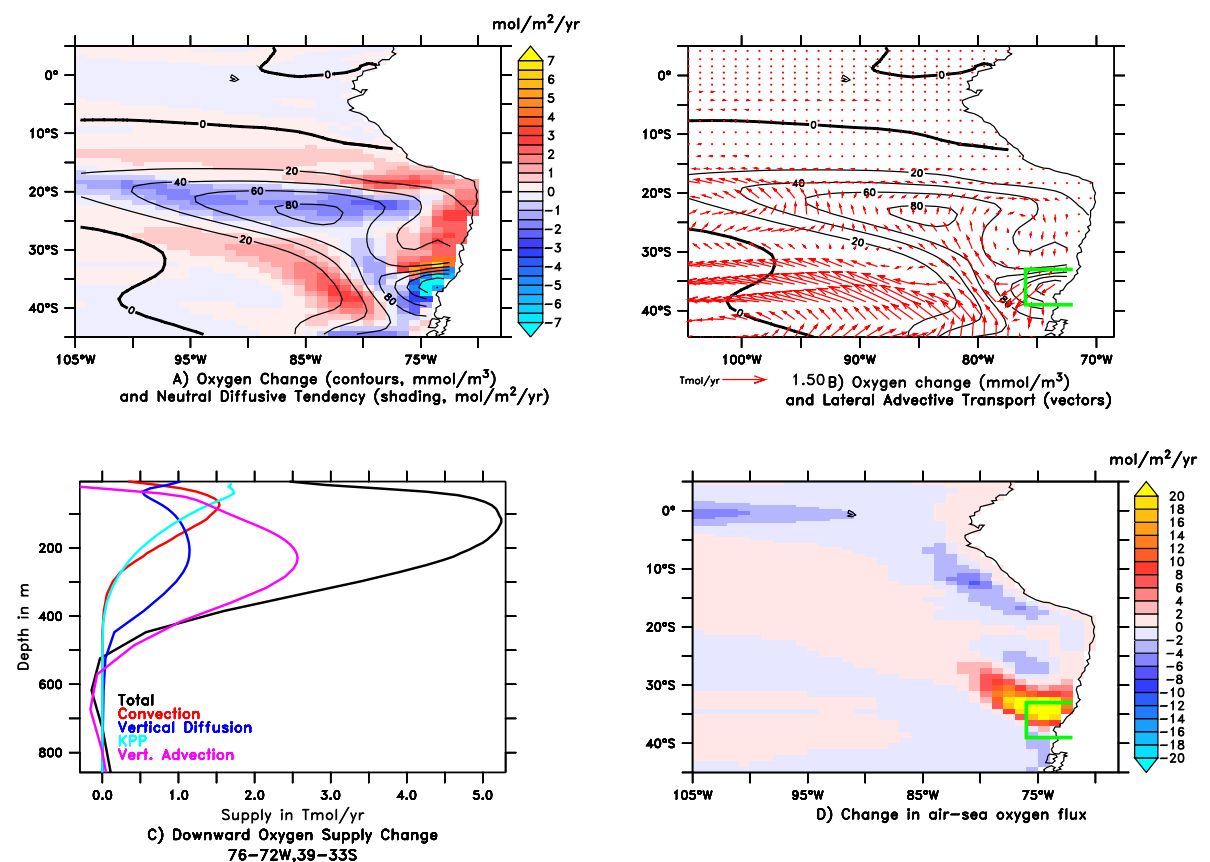

Fig. 4. $\mathrm{O}_{2}$ changes in the Southeast Pacific from years 2281-2300 in the A2 scenario relative to the corresponding years in the $1860 \mathrm{Control}$. (A) Contours: oxygen change in $\mu \mathrm{M}$ between the $\mathrm{A} 2$ and Control runs averaged over 300-500 m. Shading: change in $\mathrm{O}_{2}$ flux due to mesoscale eddy mixing in mol m $\mathrm{m}^{-2} \mathrm{yr}^{-1}$. (B) Change in the lateral advective flux of $\mathrm{O}_{2}$ between 300 and $500 \mathrm{~m}$. Green lines outline region between $76^{\circ} \mathrm{W}$ and $72^{\circ} \mathrm{W} 39^{\circ} \mathrm{S}$ and $33^{\circ} \mathrm{S}$. (C) Change in downward flux of $\mathrm{O}_{2}$ due to vertical advective and diffusive processes integrated over $76-72^{\circ} \mathrm{W}, 39-33^{\circ} \mathrm{S}$. (D) Change in air-sea $\mathrm{O}_{2}$ flux in $\mathrm{mol} \mathrm{m}^{-2} \mathrm{yr}^{-1}$ in the Southeast Pacific.

Why does the isopycnal diffusion of $\mathrm{O}_{2}$ increase? Examining the neutral diffusive tendency of $\mathrm{O}_{2}$ integrated between 300 and $500 \mathrm{~m}$, we find a large increase off the Chilean coast (colors Fig. 4a), with additional fluxes of up to $7 \mathrm{~mol} \mathrm{~m}^{-2} \mathrm{yr}^{-1}$. Over these depths alone, the additional supply is $1.6 \mathrm{Tmol} \mathrm{yr}^{-1}$. The increased diffusion into this region is associated with a plume of higher $\mathrm{O}_{2}$ (contours, Fig. 4a) emanating from the Chilean coast, and hugging the edge of the oxygen minimum zone. The lateral eddy diffusion acts to smooth out this change, with negative values in the center of the plume of higher $\mathrm{O}_{2}$ and positive values on the edges. The plume of high $\mathrm{O}_{2}$ is associated with an increase in the advective flux of $\mathrm{O}_{2}$ (Fig. 4b) which brings an additional $1.6 \mathrm{Tmol} \mathrm{yr}^{-1}$ across a latitude of $32^{\circ} \mathrm{S}$ between the longitudes of $82^{\circ} \mathrm{W}$ and $78^{\circ} \mathrm{W}$ and between depths of $300 \mathrm{~m}$ and $500 \mathrm{~m}$. This additional flux emanates from a patch of higher 


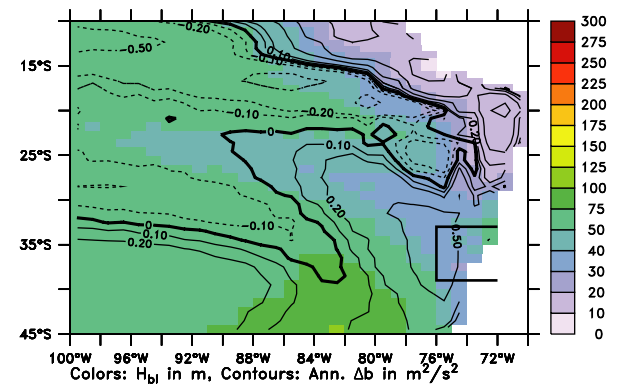

A) Max $\mathrm{H}_{b}$ and Buoyancy Add.:Control

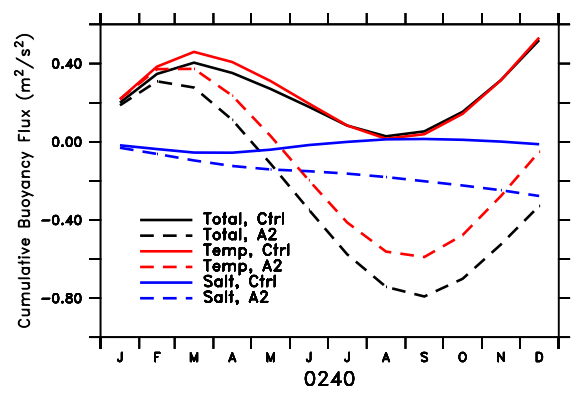

C) Cum. Buoy. Flux, 76-72w,39-33s

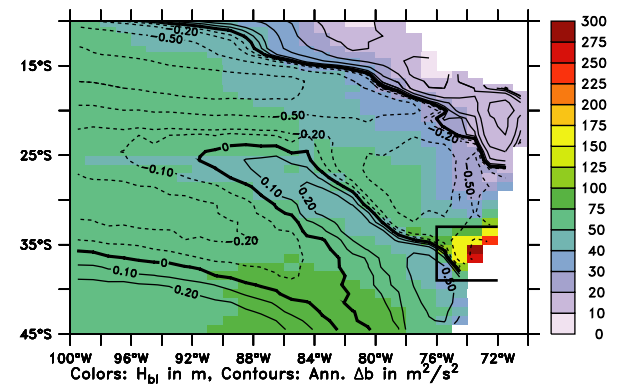

B) Max $\mathrm{H}_{b}$ and Buoyancy Add.:A2

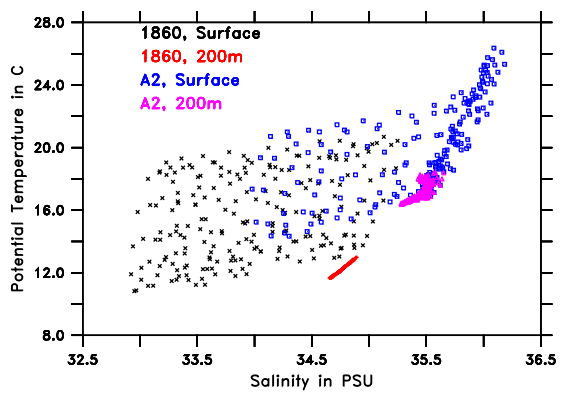

D) T-S plots, $76-72 \mathrm{~W}, 39-33 \mathrm{~S}$

Fig. 5. Physical mechanisms behind increased $\mathrm{O}_{2}$ supply to the Southeast Pacific. (A) Maximum monthly-averaged boundary layer depth in $\mathrm{m}$ (depth of active mixing from KPP code) and annually integrated buoyancy flux $\Delta B$ in $\mathrm{m}^{2} \mathrm{~s}^{-2}$ (Eq. 3) in 1860 Control. Contours are at $0, \pm 0.1, \pm 0.2, \pm 0.5, \pm 1$ and \pm 2 . (B) Maximum monthly-averaged boundary layer depth and $\Delta B$ in A2 run years 2281-2300, contours as in (A). (C) Cumulative buoyancy flux from $76^{\circ} \mathrm{W}-72^{\circ} \mathrm{W}, 39^{\circ} \mathrm{S}-33^{\circ} \mathrm{S}$. Total is shown in black, contribution from temperature in red, and contribution from salinity in blue. Control runs are solid lines, while A2 is dashed. (D) Monthly T-S plots for all ocean grid points between $76^{\circ} \mathrm{W}-72^{\circ} \mathrm{W}, 39^{\circ} \mathrm{S}-33^{\circ} \mathrm{S}$. Black symbols show surface points and red symbols $200 \mathrm{~m}$ points for Control. Blue symbols show surface points and purple points show $200 \mathrm{~m}$ for A2 model.

$\mathrm{O}_{2}$ along the coast that is also associated with increased lateral diffusive loss in Fig 4a. Outlined by the green box in Fig. $4 \mathrm{~b}$, the large coastal $\mathrm{O}_{2}$ increase extends from $39^{\circ} \mathrm{S}$ to $33^{\circ} \mathrm{S}$ and $76^{\circ} \mathrm{S}$ to $72^{\circ} \mathrm{W}$.

The vertical transport of $\mathrm{O}_{2}$ within this region is shown in Fig. 4c. The total downward transport of $\mathrm{O}_{2}$ in this region increases by more than $5 \mathrm{Tmol} \mathrm{yr}^{-1}$ (black line), an increase sufficient to explain the increase in the both the lateral diffusive export and lateral advective export seen in Fig. $4 a$ and $b$. Near the surface the dominant increase comes from transport associated with convection (red line) and nonlocal mixing associated with the K-Profile Parameterization (Large et al., 1994; light blue line). Both of these terms show some signal down to $500 \mathrm{~m}$ indicating that at some point during the $20 \mathrm{yr}$ time period the mixed layer penetrates to these depths. Below about $200 \mathrm{~m}$, however, the dominant terms supplying higher $\mathrm{O}_{2}$ to depth are the large-scale vertical advection (purple line) and the small-scale vertical diffusion that parameterizes the mixing from breaking internal waves (blue line), so that there is a "handoff" between mixed layer and interior processes between 200 and $300 \mathrm{~m}$.

The downward transport of $\mathrm{O}_{2}$ is associated with an enhanced air-sea $\mathrm{O}_{2}$ flux at the ocean surface. Figure $4 \mathrm{~d}$ shows a patch of greatly increased flux into the ocean located off the
Chilean coast slightly offset to the north of the region where $\mathrm{O}_{2}$ inventories increase at $300-500 \mathrm{~m}$ depth. Integrated from $40^{\circ} \mathrm{S}$ to $30^{\circ} \mathrm{S}$ and $80^{\circ} \mathrm{W}$ to $72^{\circ} \mathrm{W}$ the total increase in air sea flux is $6 \mathrm{Tmol} \mathrm{yr}^{-1}$. While this is a small change relative to the more than $240 \mathrm{Tmol} \mathrm{yr}^{-1}$ of total outgassing in the tropics it is more than sufficient to explain the additional vertical supply in Fig. 4c.

These changes in vertical transport are reflected in the mean hydrography. Although the term balances are more sensitive diagnostics of whether mixed layer processes transport $\mathrm{O}_{2}$, an increase in mixed layer depth is seen in this region under global warming. Figure 5a shows the maximum monthly climatological boundary layer depths (as calculated from the KPP mixed layer code) off South America for the Control model. These depths represent the average depth to which active mixing occurs over one month. Note that the boundary layers do have a local maximum off of central Chile, even in this simulation, but that it only penetrates to around $65 \mathrm{~m}$, in rough agreement with observations of the region (Silva and Guzman, 2006; Sobarzo et al., 2007). 


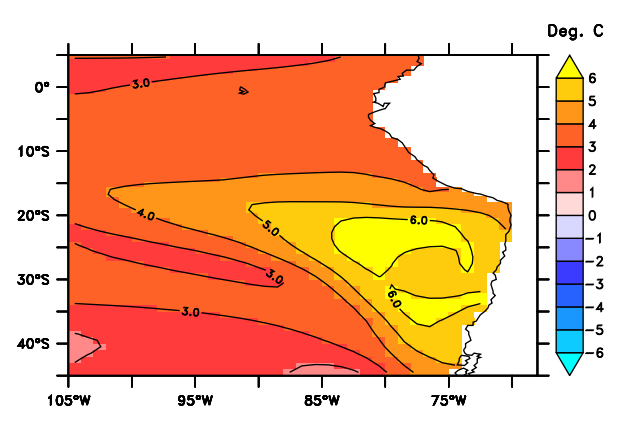

(A) $300 \mathrm{~m}$ Temperature Change A2-Control

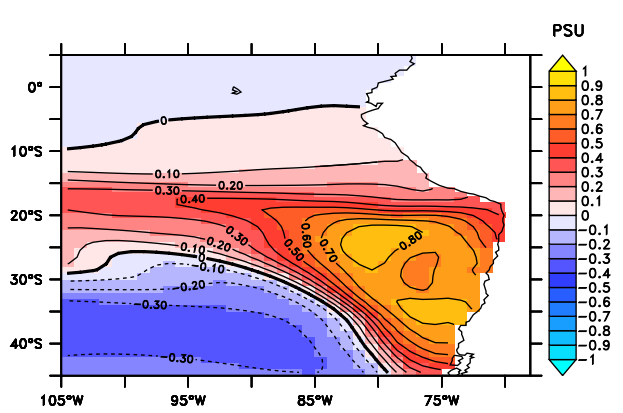

(B) $300 \mathrm{~m}$ Salinity Change A2-Control

Fig. 6. (A) Change in average temperature at $300 \mathrm{~m}$ between the A2 Scenario averaged from years 2281-2330 and the corresponding years from 1860 Control. (B) Same as A but for salinity in PSU.

The annually integrated buoyancy flux $\Delta B$ can be calculated as

$\Delta B=\int\left(-\frac{g \alpha Q}{\rho c_{p}}+g \beta S F_{\mathrm{w}}\right) \mathrm{d} t \equiv \Delta B_{\mathrm{T}}+\Delta B_{\mathrm{S}}$

where $g$ is the gravitational acceleration, $\alpha$ is the coefficient of thermal expansion, $Q$ is the surface heat flux, $\rho$ is the density of seawater, $c_{p}$ is the specific heat, $\beta$ is the coefficient of haline contraction, $S$ is the salinity, $F_{\mathrm{w}}$ is the freshwater flux and an integral is taken over the entire year. $\Delta B_{\mathrm{T}}$ and $\Delta B_{\mathrm{S}}$ can then be defined as the thermal and haline components of $\Delta B$, corresponding to the first and second terms under the integral. In the Control simulation, the Central Chilean coast is a region of positive buoyancy flux, as are the very shallow mixed layers further to the north.

In the A2 scenario, by contrast (Fig. 5b), the boundary layer depth off Chile reaches $290 \mathrm{~m}$ and mixed layer depths (defined using a density criterion as in global climatologies) reach $440 \mathrm{~m}$ or more at individual grid points. While such deep mixed layers may seem surprising, the modern ARGObased climatology of Holte et al. (2010) does show maximum mixed layer depths exceeding $200 \mathrm{~m}$ over large parts of the Southeast Pacific during Austral winter in regions which in the Control model are associated with annual-mean buoyancy loss. Under global warming the Central Chilean coast also becomes a region with negative $\Delta B$, so that surface fluxes act to make the waters denser.

The contributors to $\Delta B$ in the control region $39-33^{\circ} \mathrm{S}$, $76-72^{\circ} \mathrm{W}$ off the Central Chilean coast are analyzed in Fig. 5c, which shows cumulative fluxes integrated through the year and Table 3, which breaks down the annual mean contributors to the heat and freshwater fluxes. In the Control, the wintertime cooling is much less than the summertime warming and the freshwater balance is near neutral with significant runoff in the autumn and winter. Both the net heating over the year and freshening during winter help to limit the penetration of convection in the model as in the real world (Sobarzo et al., 2007). Under global warming, the heat balance becomes slightly negative during the year, switch- ing sign from +30 to $-9 \mathrm{~W} \mathrm{~m}^{-2}$. This change is largely the result of an increase in evaporative cooling during the wintertime. Additionally, the freshwater balance becomes negative throughout the season, so that the hydrological cycle acts to make surface waters much denser. The net freshwater flux in the control region drops by more than $1 \mathrm{~m} \mathrm{yr}^{-1}$. This is one of the largest declines in freshwater supply to the ocean seen in mid-latitudes under global warming. About half of the drop is due to increased evaporation, while the remainder is due to a $75 \%$ reduction in runoff and a decline in in-situ precipitation. On a seasonal scale, the heat fluxes have the biggest impact on the buoyancy fluxes, but when the integral over the entire year is taken, the freshwater fluxes play the dominant role in the net extraction of buoyancy from this region.

The impact of the reduced freshwater flux can be seen in a T-S plot of the region (Fig. 5d). In the Control simulation surface waters (black points) are always much fresher and lighter than waters at $200 \mathrm{~m}$ (red points), with a difference quite similar to that seen in observations. In the A2 simulation the surface waters (blue points) become much saltier. This increasing salinification brings the surface waters much closer to the waters at $200 \mathrm{~m}$ (magenta points) and preconditions the column for wintertime convection. The T-S plot off central Chile under global warming is much more like the modern ocean off of Southeast Australia, where deep mixed layers are currently seen in salty, subtropical waters (Holte et al., 2010). The increase in deep temperature and salinity is seen throughout the region where $\mathrm{O}_{2}$ increases (Fig. 6a, b), so that the change is visible in classical hydrographic quantities as well as in age and $\mathrm{O}_{2}$.

These changes in heat and freshwater balance reflect larger-scale changes in the atmospheric circulation over the Southeast Pacific. As shown in Fig. 7a, under global warming in CM2.1 the subtropical high over the Southeast Pacific strengthens and the winds over central Chile shift from being off the ocean to more along the coast. As a result, less moisture is brought into this region, resulting in a sharp decline in precipitation (Fig. 7b) and a significant drop in relative 


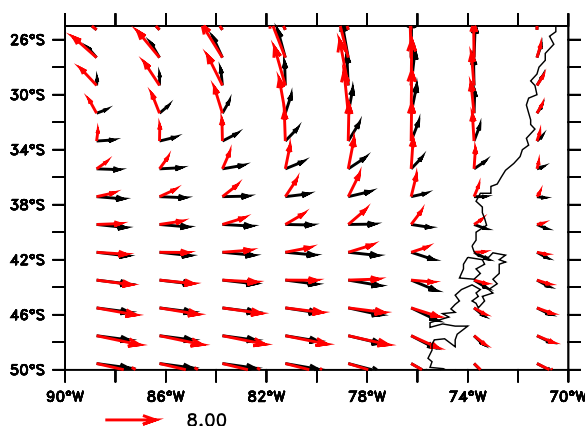

A) Surface Wind in Pa 1860, A2

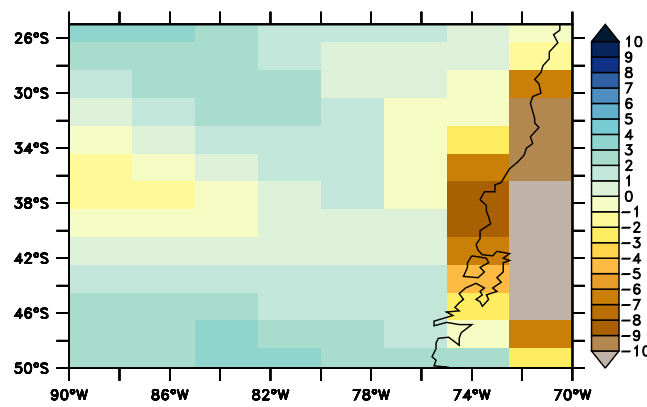

C) $\Delta \mathrm{RH}_{\text {ref }}$ in Percent $\mathrm{A} 2-1860$

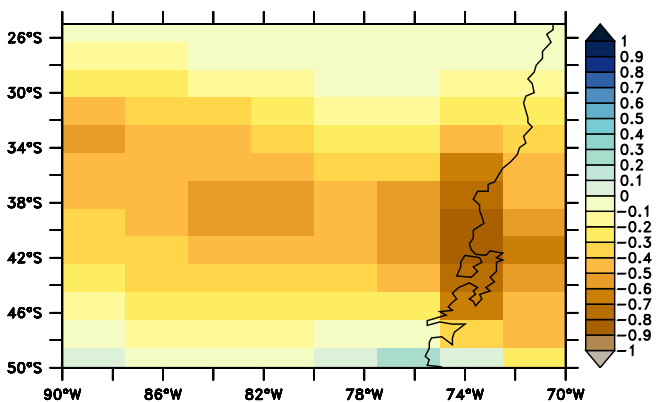

B) $\Delta$ Precip in $m / y r ~ A 2-1860$

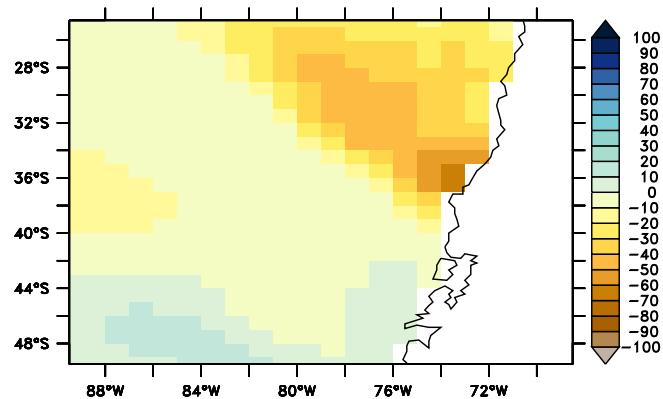

D) $\Delta$ Latent Heat flux in $\mathrm{W} / \mathrm{m}^{2} \mathrm{~A} 2-1860$

Fig. 7. Atmospheric changes under global warming in the Southeast Pacific. (A) Annual-mean surface winds for years 521-540 1860 control (black) and years 2281-2300 of A2 scenario (red). (B) Change in precipitation in $\mathrm{m} \mathrm{yr}^{-1}$. (C) Change in relative humidity in \%. (D) Change in latent heat flux (negative is loss from ocean) in $\mathrm{W} \mathrm{m}^{-2}$.

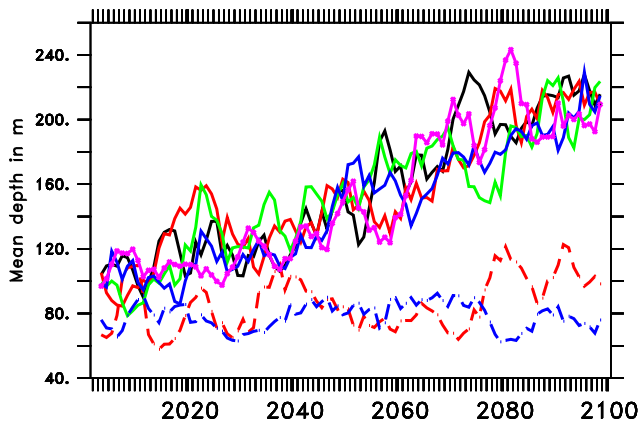

(A) August MLD, 76-72W 39-33S

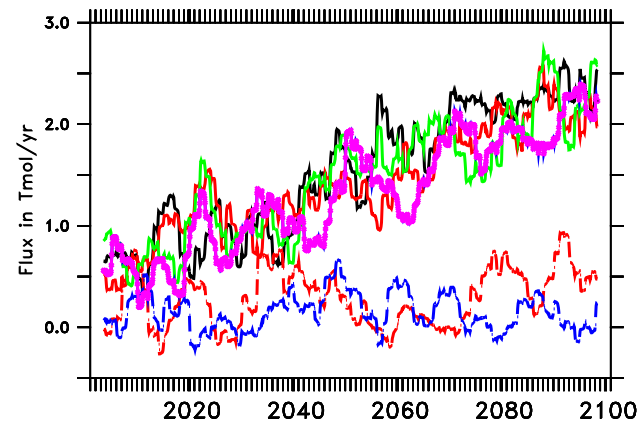

(b) Air-sea oxygen flux 76-72W,39-33S

Fig. 8. Changes under increasing $\mathrm{CO}_{2}$ for a range of versions of the ESM2.1 model. Solid black line shows A2 scenario. Solid colored lines show simulations using the A1B scenario where $\mathrm{CO}_{2}$ affected radiation balance but not necessarily ocean or land biogeochemistry (lines 4-7, Table 1). Dashed colored lines show simulations where $\mathrm{CO}_{2}$ affects biogeochemical cycling (through acidification or terrestrial carbon fertilization, lines 8 and 9 of Table 1) but not radiation. (A) Monthly-mean mixed layer depth for August, five-year boxcar smoothed for all ocean grid points between $76^{\circ} \mathrm{W}-72^{\circ} \mathrm{W}$ and $39^{\circ} \mathrm{S}-33^{\circ} \mathrm{S}$. (B) Five-year smooth of air-sea flux of $\mathrm{O}_{2}$ in $\mathrm{Tmol} \mathrm{yr}^{-1}$ for same region. Lines as in $(\mathrm{A})$. 
Table 3. Annual mean heat, annually integrated water, and annual integrated buoyancy fluxes off Central Chilean coast $\left(76^{\circ} \mathrm{W}-\right.$ $72^{\circ} \mathrm{W}, 39^{\circ} \mathrm{S}-33^{\circ} \mathrm{S}$ ) for years $2281-2300$ in the A2 run and $221-$ 240 in the 1860 Control run. Heat fluxes in $\mathrm{W} \mathrm{m}^{-2}$, water fluxes in $\mathrm{m}$, and integrated buoyancy fluxes in $\mathrm{m}^{2} \mathrm{~s}^{-2}$.

\begin{tabular}{lrr}
\hline & $\begin{array}{r}1860 \\
\text { Control }\end{array}$ & A2 \\
\hline Heat fluxes & & \\
\hline Net Shortwave & 199 & 214 \\
Net Longwave & -78 & -84 \\
Sensible heat flux & -13 & -16 \\
Latent heat flux & -80 & -123 \\
Total heat flux & 30 & -9 \\
\hline Water fluxes & & \\
\hline Precipitation & 0.51 & 0.32 \\
Runoff & 0.37 & 0.08 \\
Evaporation & 1.00 & 1.55 \\
Total water flux & -0.11 & -1.15 \\
\hline Buoyancy fluxes & & \\
\hline Integrated buoyancy flux & 0.55 & -0.12 \\
from temperature & & \\
Integrated buoyancy flux & -0.03 & -0.30 \\
from freshwater forcing & & \\
Integrated buoyancy flux & 0.52 & -0.43 \\
\hline
\end{tabular}

humidity of up to $13 \%$ (Fig. 7c). While the CM2.1 model is somewhat extreme in its prediction of such large precipitation changes, most of the IPCC AR4 models examined by Vera et al. (2007) show drying in this region, with all seven models showing drying during the high-precipitation period of April-June. The drop in relative humidity then results in much higher evaporation and latent cooling of the ocean (Fig. 7d and Table 3).

The robustness of these results cannot be easily evaluated when using a single model code. On the one hand, given that the real ocean exhibits even deeper convection in the Southeast Pacific (Holte et al., 2010) than in our model the model's dynamical response of enhanced convection under drying conditions is not unreasonable. On the other hand, it is somewhat worrisome that the establishment of a convective pathway is limited to a relatively small area, with maximum monthly mixed layer depths exceeding $200 \mathrm{~m}$ at only ten grid points under global warming in the Southeast Pacific.

We can, however, evaluate whether this result holds across different configurations of the same model. Figure 8 compares the mixed layer depth and air-sea $\mathrm{O}_{2}$ fluxes off Chile to a suite of runs made using the A1B scenario as described above. As seen in Fig. 8a, all the runs in which carbon dioxide has an impact on the radiative balance show an increase in the August mixed layer depth (smoothed over five years) off Chile over the 21 st century. There is little difference be- tween the A2 scenario (black line) the radiatively forced A1B scenarios (colored solid lines) over the course of the century. Neither of the runs without radiative forcing (colored dashed lines) show this increase in mixed layer depth, with a clear separation between the two families of curves as early as 2040. The five-year average of the air-sea $\mathrm{O}_{2}$ flux off Chile (Fig. 8b) shows a similar behavior, with interdecadal variations that are clearly correlated with variations in the mixed layer depth. That a similar linkage between global warming, increasing mixed layer depths and increasing ocean uptake of $\mathrm{O}_{2}$ exists across these runs within the 21 st century suggests that our results do not exhibit sharp thresholds that depend sensitively on the degree of forcing. Nor is the difference between the A2 and 1860 control simulations an artifact arising from natural variability in this particular pair of simulations. We recognize, however, that the degree to which such an increase actually reaches depths that provide a direct pathway to suboxic waters may be strongly model-dependent.

\section{Discussion and conclusions}

We have shown that $\mathrm{O}_{2}$ concentrations exhibit a complicated response to climate change because of changes in circulation involving multiple physical processes. Separating out budgets by depth range, the changes in $\mathrm{O}_{2}$ are linked to changes in the advective flux of older deep waters into intermediate depths. This reflects the dominant role played by advection (Fig. 1d) in the overall budget of $\mathrm{O}_{2}$ within the deep ocean. When budgets are computed using an isolevel of $\mathrm{O}_{2}$ to define a fixed volume, however, parameterized lateral mixing becomes the most important term. Within suboxic zones such as that off South America, this additional supply of $\mathrm{O}_{2}$ along isopycnals is fed by changes in convection and vertical mixing associated with salinification of the surface ocean off Chile. Our results suggest that the simulated changes in the volume of suboxic water in climate models can depend sensitively on changes in the heat and salt balance in nearby convective regions. They also imply that simplified advectiondiffusion models should be used with caution in projecting the behavior of suboxic waters into the future, as such models are unlikely to capture the details of ventilation of these rather special locations.

Our results also highlight the importance of representing isopycnal mixing correctly. While the isopycnal tracer diffusion coefficient (as opposed to the layer thickness diffusion coefficient) has been found to have a relatively minor impact on the circulation within our coupled models these results suggest that it has a big impact on the degree of suboxia that develops within the tropics. The isopycnal tracer diffusion coefficient in ESM2.1 is set to a spatially and temporally constant isotropic value of $600 \mathrm{~m}^{2} \mathrm{~s}^{-1}$ (Gnanadesikan et al., 2006) that is higher than values estimated from satellite altimetry (Stammer, 1998) which are generally less than about $250 \mathrm{~m}^{2} \mathrm{~s}^{-1}$ in the eastern basins. However, when Ollitraut 
and Colin de Verdiere (2002) used floats to estimate diffusion coefficients the North Atlantic they found much larger values of $5400 \mathrm{~m}^{2} \mathrm{~s}^{-1}$ in the western basin and $1900 \mathrm{~m}^{2} \mathrm{~s}^{-1}$ in the eastern basin. This would suggest that our values of diffusion coefficient should be larger and spatially dependent. Additionally, it is not clear that the diffusion coefficient should be isotropic. Ledwell et al. (1998) found an along-isopycnal diffusion coefficient between $800-2200 \mathrm{~m}^{2} \mathrm{~s}^{-1}$ in the zonal direction and between $300-1100 \mathrm{~m}^{2} \mathrm{~s}^{-1}$ in the meridional direction based on the release of a passive tracer. Part of the wide range may stem from disagreement of how to separate dispersion due to the small-scale Rossby waves which would be marginally resolved by our coupled model from those due to transient eddies with closed circulation which would not be resolved. A major conclusion of this paper is that such an uncertainty must be resolved in order to better model lowoxygen zones in the open ocean. We would expect that models that use lower values of isopycnal diffusion coefficient would simulate overly large volumes of suboxic water. If in fact the isopycnal diffusion coefficient in our models is too small, as suggested by the tracer release and float results, this could help to explain why our model generates excessively intense hypoxia.

Our results also suggest that recent attribution of increases in the volume of hypoxic waters may depend strongly on the precise definition of hypoxia used for analysis. Hypoxia associated with changes in the distribution of fish (a relatively high $\mathrm{O}_{2}$ threshold) would be expected to increase under global warming. However, if local increases in suboxia (with a relatively low $\mathrm{O}_{2}$ threshold) are observed in the next few decades, explanations for such changes should be sought in long-period climate variability as well as secular changes associated with global warming. Conversely, if $\mathrm{O}_{2}$ was found to increase in the suboxic oxygen minimum zones, such increases could be consistent with global warming even as $\mathrm{O}_{2}$ in the broader ocean decreases.

We caution that our projection that warming does not necessarily lead to increased suboxic volume should not be extrapolated to all climates. As our simulations focus on a few centuries of warming and on the open ocean, they are not inconsistent with suboxia developing over time scales of many centuries in the deep ocean or over shorter periods in coastal waters. Given increasing evidence that much of the impact of greenhouse gas emissions will persist for millennia (Schmitther et al., 2008) this possibility deserves further study. Our results also suggest that a reinvigorated ocean overturning circulation could increase suboxia as deep, low-oxygen waters are advected into the oxygen minimum zones.

Finally, it should be acknowledged that modelled increases in mid-depth $\mathrm{O}_{2}$ in the current generation of Earth System models may reflect some common failings in model formulation. These failings may be related to representation of physical modes of ventilation and overly simplistic representation of how biology sets the regional pattern and depth scale of remineralization. Resolving this issue is of crit- ical importance for understanding the potential impacts of climate change on ocean biogeochemical cycles and interior ocean habitat for fish, particularly in the light of paleoclimatic results suggesting that anoxic events associated with global warming could have caused mass extinctions such as that at the end of the Permian (e.g., Wignall and Twichett, 1996).

Acknowledgements. We thank Ryan Rykaczewski, Daniele Bianchi, Jorge Sarmiento and Thomas Frölicher for useful discussions and comments on this manuscript. We thank Francois Primeau, Galen McKinley, Leticia Cotrim da Cunha and an anonymous reviewer for constructive reviews.

Edited by: L. Cotrim da Cunha

\section{References}

Bianchi, D.: Processes controlling the distribution of biogeochemical tracers in the ocean, Ph.D. Thesis, Princeton Univ., 2011.

Bopp, L., Le Quere, C., Heimann, M., Manning, A. C., and Monfray, P.: Climate-induced oceanic oxygen fluxes: Implications for the contemporary budget, Glob. Biogeochem. Cy., 16, 1022, doi:10.1029/2001GB001445, 2002.

Bryan, F. O., Danabasoglu, G., Gent, P. R., and Lindsay, K.: Changes in ocean ventilation during the 21 st century in the CCSM3, Ocean Model., 15, 141-156, 2006.

Delworth, T. L., Broccoli, A. J., Rosati, A., Stouffer, R. J., Balaji, V., Beesley, J. A., Cooke, W. F., Dixon, K. W., Dunne, J., Dunne, K. A., Durachta, J. W., Findell, K. L., Ginoux, P., Gnanadesikan, A., Gordon, C. T., Griffies, S. M., Gudgel, R., Harrison, M. J., Held, I. M., Hemler, R. S., Horowitz, L. W., Klein, S. A., Knutson, T. R., Kushner, P. J., Langenhorst, A. R., Lee, H.-C., Lin, S.-J., Lu, J., Malyshev, S. L., Milly, P. C. D., Ramaswamy, V., Russell, J., Schwartzkopf, M. D., Shevliakova, E., Sirutis, J. J., Spelman, M. J., Stern, W. F., Winton, M., Wittenberg, A. T., Wyman, B., Zeng, F., and Zhang, R.: GFDL's CM2 global coupled climate models - Part 1: Formulation and simulation characteristics, J. Climate, 19, 643-674, 2006.

Devol, A. H. and Hartnett, H. E.: Role of the oxygen-deficient zone in transfer of organic carbon to the deep ocean, Limnol. Oceanogr., 46, 1684-1690, 2001.

Dunne, J. P., Armstrong, R. A., Gnanadesikan, A., and Sarmiento, J. L.: Empirical and mechanistic models of particle export, Global Biogeochem. Cy., 19, GB4026, doi:10.1029/2004GB002390, 2005.

Dunne, J. P., Gnanadesikan, A., Sarmiento, J. L., and Slater, R. D: Technical description of the prototype version (v0) of Tracers of Phytoplankton with Allometric Zooplankton (TOPAZ) ocean biogeochemical model as used in the Princeton IFMIP model, Biogeosciences, 7, 3593, Supplement, available at: http://www.biogeosciences.net/7/3593/2010/ bg-7-3593-2010-supplement.pdf, 2010.

Duteil, O. and Oschlies, A.: Sensitivity of simulated extent and future evolution of marine suboxia to mixing intensity, Geophys. Res. Lett., 38, L06607, doi:10.1029/2011GL046877, 2011.

Frölicher, T., Joos, F., Plattner, G.-K., Steinacher, M., and Doney, S. C.: Natural variability and anthropogenic trends in oceanic oxygen in a coupled carbon-cycle climate model ensemble, Global 
Biogeochem. Cy., 23, GB1003, doi:10.1029/2008GB003316, 2009.

Garcia, H. E., Locarnini, R. A., Boyer, T. P., Antonov, J. I., Baranova, O. K., Zweng, M. M., and Johnson, D. R.: Dissolved Oxygen, Apparent Oxygen Utilization and Oxygen Saturation, in: World Ocean Atlas 2009 Volume 3, edited by: Levitus, S., NOAA Atlas, NESDIS 70, US Government Printing Office, Washington, D.C., 344 pp., 2010.

Gnanadesikan, A., Dixon, K. W., Griffies, S. M., Balaji, V., Barreiro, M., Beesley, J. A., Cooke, W. F., Delworth, T. L., Gerdes, R., Harrison, M. J., Held, I. M., Hurlin, W. J., Lee, H. C., Liang, Z., Nong, G., Pacanowski, R. C., Rosati, A., Russell, J. L., Spelman, M., Samuels, B. L., Song, Q., Spelman, M. J., Stouffer, R. J., Sweeney, C., Vecchi, G., Winton, M., Wittenberg, A., Zeng, F., Zhang, R., and Dunne, J. P.: GFDL's CM2 global coupled climate models - Part 2: The baseline ocean simulation, J. Climate, 19, 675-697, 2006.

Gnanadesikan, A., Russell, J. L., and Fanrong Zeng: How does ocean ventilation change under global warming?, Ocean Sci., 3, 43-53, doi:10.5194/os-3-43-2007, 2007.

Gnanadesikan, A., Dunne, J. P., and John, J.: What ocean biogeochemical models can tell us about bottom-up control of ecosystem variability, ICES J. Mar. Sci., 68, 1030-1044, doi:10.1093/icesjms/fsr068, 2011.

Griffies, S. M., Gnanadesikan, A., Pacanowski, R. C., Larichev, V. D., Dukowicz, J. K., and Smith, R. D.: Isoneutral diffusion in a Z-coordinate ocean model, J. Phys. Oceanogr., 28, 805-830, 1998.

Holte, J., Gilson, J., Talley, L., and Roemmich, D.: Argo Mixed Layers, Scripps Institution of Oceanography/UCSD, available at: http://mixedlayer.ucsd.edu (last access: 22 June 2011), 2010.

Large, W. G., McWilliams, J. C., and Doney, S. C.: Oceanic vertical mixing: a review and a model with a non-local K-profile boundary layer parameterization, Rev. Geophys., 32, 363-403, 1994.

Le Quere, C., Heimann, M., Manning, A. C., and Monfray, P.: Climate-induced oceanic oxygen fluxes: Implications for the contemporary carbon budget, Global Biogeochem. Cy., 16, 1022, doi:10.1029/2001GB001445, 2002.

Ledwell, J. R., Watson, A. J., and Law, C. S.: Mixing of a tracer in the pycnocline, J. Geophys. Res., 103, 21499-21529, 1998.

Luyten, J. L, Pedlosky, J., and Stommel, H. M.: The ventilated thermocline, J. Phys. Oceanogr., 13, 292-309, 1983.

Matear, R. J. and Hirst, A. C.: Long-term changes in dissolved oxygen concentrations in the ocean caused by global warming, Global Biogeochem. Cy., 17, 1125, doi:10.1029/2002GB001997, 2003.

Matear, R. J., Hirst, A. C., and McNeil, B. I.: Changes in dissolved oxygen in the Southern Ocean with climate change, Geophys. Geochem. Geosys., 1, 1050, doi:10.1029/2000GC000086, 2000.

Morel, A. and Antoine, D.: Heating rate within the upper ocean in relation to its bio-optical state, J. Physical Oceanogr., 24, 1652$1665,1994$.

Nakicenovic, N., Alcamo, J., Davis, G., de Vries, B., Fenhann, J., Gaffin, S., Gregory, K., Grübler, A., Jung, T. Y., Kram, T., La Rovere, E. L., Michaelis, L., Mori, S., Morita, T., Pepper, W., Pitcher, H., Price, L., Riahi, K., Roehrl, A., Rogner, H.-H., Sankovski, A., Schlesinger, M., Shukla, P., Smith, S., Swart, R., van Rooijen, S., Victor, N., and Dadi, Z.: Emissions Scenarios,
Special Report, Working Group III, Intergovernmental Panel on Climate Change, Cambridge Univ. Press, Cambridge, 2000.

Ollitraut, M. and Colin de Verdiere, A.: SOFAR floats reveal midlatitude intermediate North Atlantic General Circulation. Part I: A Lagrangian descriptive view, J. Phys. Oceanogr., 32, 2020 2033, 2002.

Reichler, T. and Kim, J.: How well do coupled climate models simulate today's climate?, B. Am. Meteorol. Soc., 89, 303-311, 2008.

Russell, J. L., Stouffer, R. J., and Dixon, K. W: Intercomparison of the Southern Ocean Circulations in IPCC Coupled Model Control Simulations, J. Climate, 19, 4560-4575, doi:10.1175/JCLI3869.1, 2006.

Rykaczewski, R. and Dunne, J. P.: Enhanced nutrient supply to the California Current Ecosystem with global warming and increased stratification in an earth system model, Geophys. Res. Lett., 37, L21606, doi:10.1029/2010GL045019, 2010.

Schmittner, A., Oschlies, A., Matthews, H. D., and Galbraith, E. D.: Future changes in climate, ocean circulation, ecosystems and biogeochemical cycling simulated for a business-as-usual $\mathrm{CO}_{2}$ emission scenario until year $4000 \mathrm{AD}$, Global Biogeochem. Cy., 22, GB1013, doi:10.1029/2007GB002953, 2008.

Shaffer, G., Olsen, S. M., and Pedersen, J. O. P.: Long-term ocean oxygen depletion in response to carbon dioxide emissions from fossil fuels, Nat. Geosci., 2, 102-105, 2009.

Shevliakova, E., Pacala, S. W., Malyshev, S., Hurtt, G. C., Milly, P. C. D., Caspersen, J. P., Sentman, L. T., Fisk, J. P, Wirth, C., and Crevoisier, C.: Carbon Cycling Under 300 Years of Land-Use Change: The Importance of the Secondary Vegetation Sink, Global Biogeochem. Cy., 23, GB2022, doi:10.1029/2007GB003176, 2009.

Silva, N. and Guzman, D.: Condiciones oceanographicas fisicas y quimicas entre Boca del Guafo y Fiordo Aysen (Crucero CIMAR 7 Fiordos), Cienc. Tecnol. del Mar, 29, 24-44, 2006.

Sobarzo, M., Bravo, L., Donoso, D., Garcés-Vargas, J., and Schneider, W.: Coastal upwelling and seasonal cycles that influence the water column over the continental shelf off central Chile, Prog. Oceanogr., 75, 363-382, 2007.

Stammer, D.: On eddy characteristics, eddy transports and mean flow properties, J. Phys. Oceanogr., 28, 727-739, 1998.

Stramma, L., Schmidtko, S., Levin, L. A., and Johnson, G. C.: Ocean oxygen minima expansions and their biological impacts, Deep-Sea Res. Pt. I, 57, 587-595, 2010.

Steinacher, M., Joos, F., Frölicher, T. L., Bopp, L., Cadule, P., Cocco, V., Doney, S. C., Gehlen, M., Lindsay, K., Moore, J. K., Schneider, B., and Segschneider, J.: Projected 21st century decrease in marine productivity: a multi-model analysis, Biogeosciences, 7, 979-1005, doi:10.5194/bg-7-979-2010, 2010.

van Oldenborgh, G. J., Philip, S. Y., and Collins, M: El Niño in a changing climate: a multi-model study, Ocean Sci., 1, 81-95, doi:10.5194/os-1-81-2005, 2005.

Vera, C. M., Silvestri, G., Liebmann, B., and Gonzalez, P.: Climate change scenarios for regional precipitation in South America, Geophys. Res. Lett., 33, L13707, doi:10.1029/2006GL025759, 2007.

Wignall, P. B. and Twichett, R. J.: Oceanic anoxia and the End Permian mass extinction, Science, 272, 155-1158, 1996. 